\title{
grandes naves
}

$832 \cdot 23$

Desde el punto de vista constructivo, uno de los temas constructivos más interesantes lo ofrece la resolución de grandes naves de gran luz, cuyas estructuras se ven, además, complicadas por la necesidad de adaptación de puentes-grúa.

Para resolver estos problemas se recurrió preferentemente a las estructuras de hormigón armado, obteniéndose notables éxitos económicos gracias al empleo de la prefabricación en todos los casos posibles.

Arcos, cerchas, jácenas, viguetas, placas... surgían a ritmo acelerado de los talleres de prefabricación, al mismo tiempo que se hormigonaban "in situ" cimentaciones, pilares, soleras, en perfecta conjunción de trabajo.

$Y$ asi se resolvieron, de forma original, complicados problemas estructurales, propios de este tipo de edificación industrial, $y$ que forzaron soluciones de la audacia $y$ originalidad de las vigas $K$ de hormigón postensado de los talleres de laminación de las cerchas en arco que constituyen la cubierta de dichos talleres.

Junto a las grandes naves de laminación, ofrecen notable interés los talleres de calderería, mecánico y nave de fundición, cuyas cubiertas se han resuelto también con estructuras planas, prefabricadas a pie de obra, de hormigón armado. 


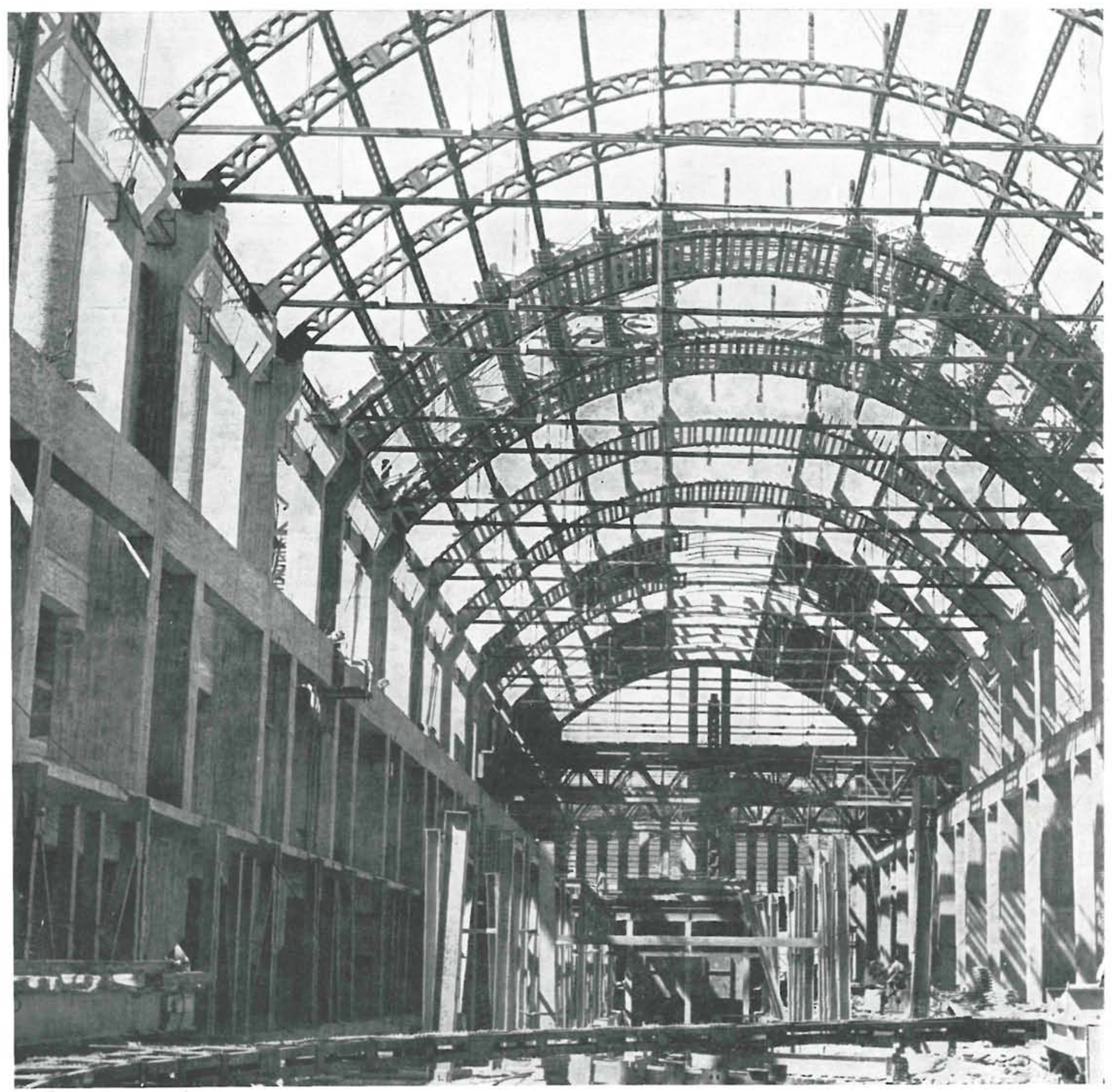

construcción

Al entrar en el edificio un tren de lingotes procedente de la acerería, dos grúas deslingotadoras eliminan mecánicamente la lingotera, permitiendo que otros dos puentes-grúa cargadores de los hornos puedan recoger individualmente los lingotes y dejarlos dentro del horno

Cuando el lingote ha alcanzado la temperatura necesaria para su laminado, es extraído de los hornos por uno de los dos puentes-grúa cargadores. 


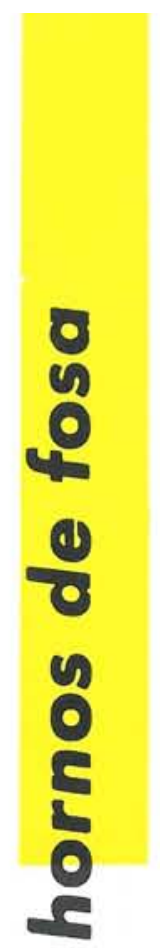

Situados en el extremo oeste de los talleres de laminación, su nave ocupa una extensión de $5.500 \mathrm{~m}^{2}$. Por su parte norte penetran tres vías que la unen al edificio de hornos de acero, dedicándose dicha zona al almacenamiento de lingoteras y lingotes fríos.

Este almacenamiento

de lingotes actúa de volante entre la acerería y el taller de laminación, haciendo posible la marcha continua de éste con las coladas periódicas de aquélla.

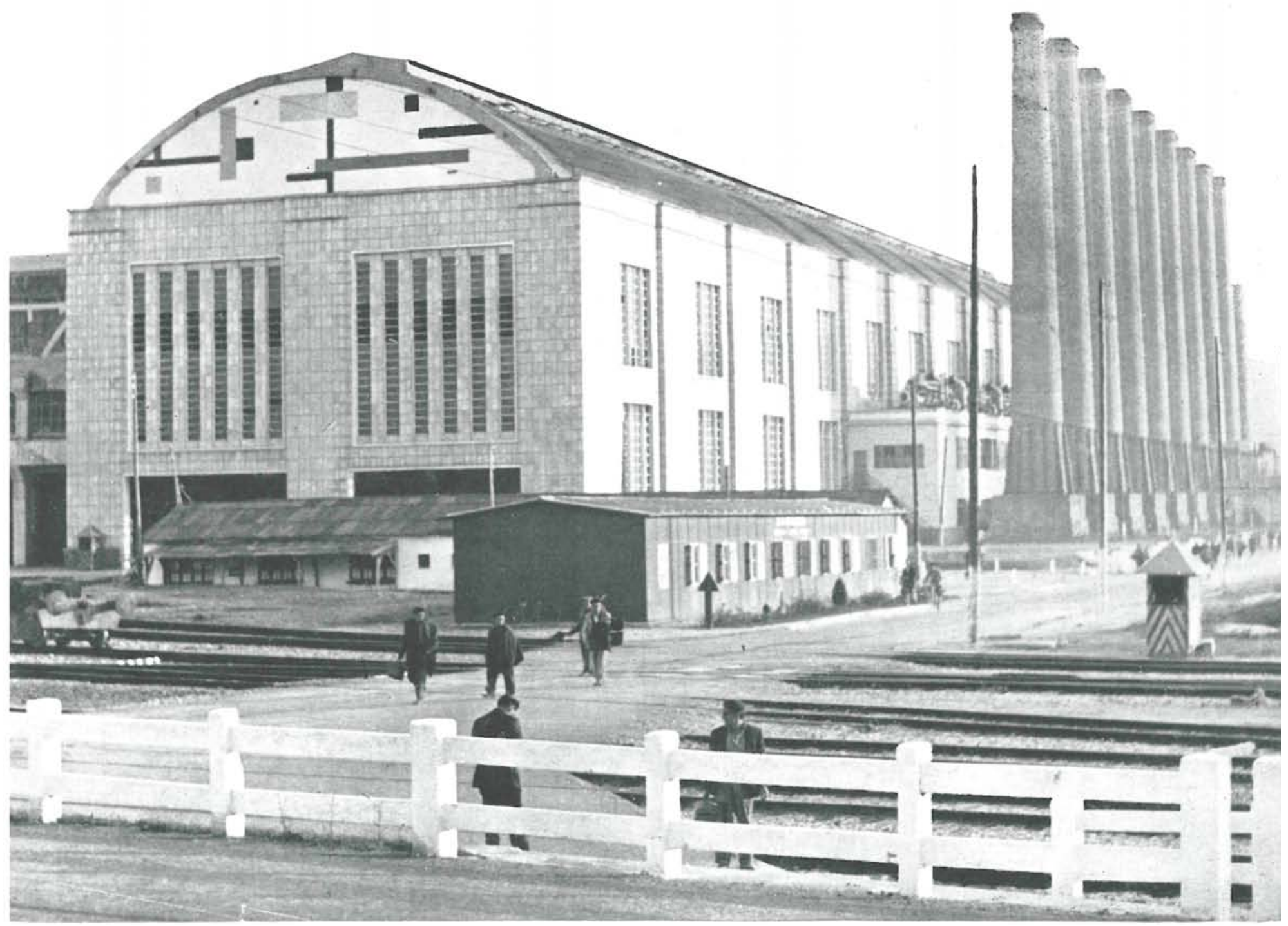



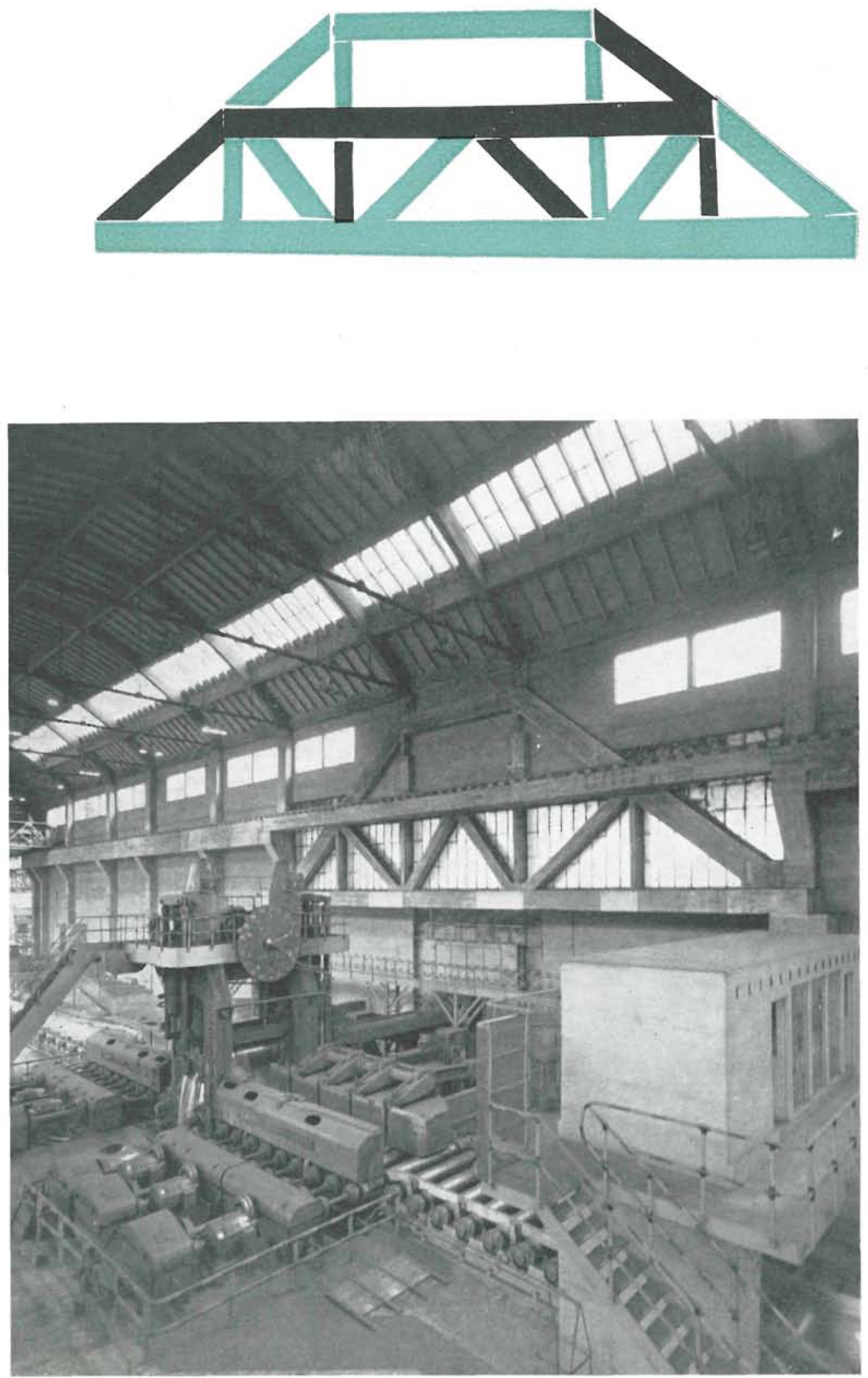

Las instalaciones de laminación correspondientes a la primera etapa son las siguientes: un gran tren desbastador, capaz de laminar hasta $1.000 .000 \mathrm{de}$ toneladas de lingote de acero para producir desbastes destinados

a la fabricación de perfiles, carriles y productos planos; un tren estructural de tres cajas,

duo reversible, con capacidad de producción de 310.000 toneladas de productos laminados; un tren de chapa gruesa, capaz de producir hasta 600.000 toneladas de diversos espesores; un tren reversible para la laminación de banda caliente, capaz para 550.000 toneladas de diversos espesores; un tren continuo de tres cajas para laminar banda en frío, capaz de producir 300.000 toneladas anuales. 


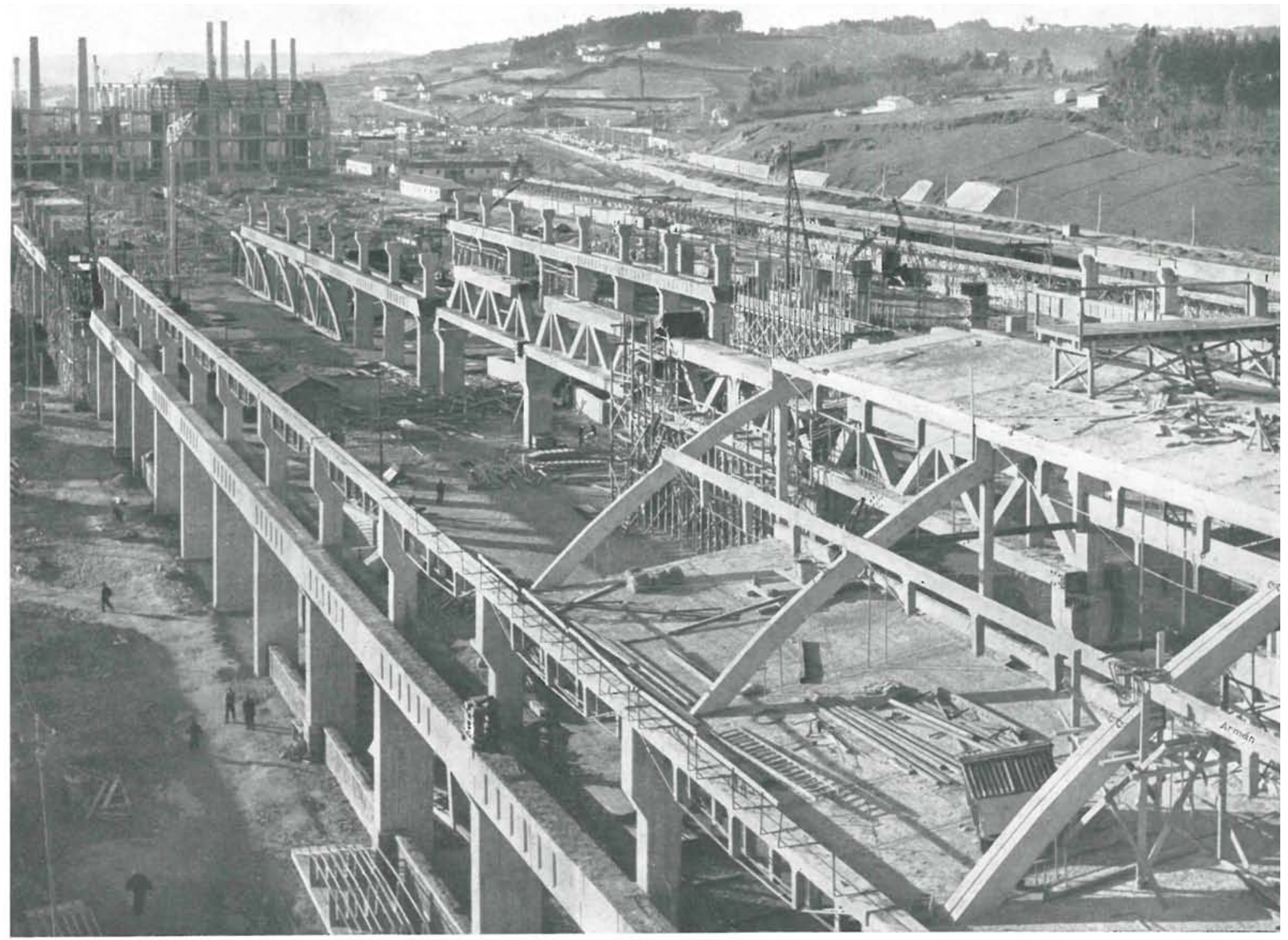

construcción

Solamente aquellas partes que por su complejidad o especialización la industria nacional no ha podido construir, han sido importadas del extranjero.

El resto de la maquinaria,

que supera el $80 \%$ del tonelaje total anteriormente señalado, ha sido construído o está en período de ejecución en distintos talleres españoles, utilizando planos de las citadas casas extranjeras o nuevos planos ejecutados por el Departamento de laminación.

La ejecución de la obra de cimentaciones tiene una importancia excepcional. En cuanto al volumen de obra, dará idea el hecho de que supera en cuanto a número de cajones hincados, pilotes y redondos empleados, a la suma de los empleados en todo el resto de la obra. 

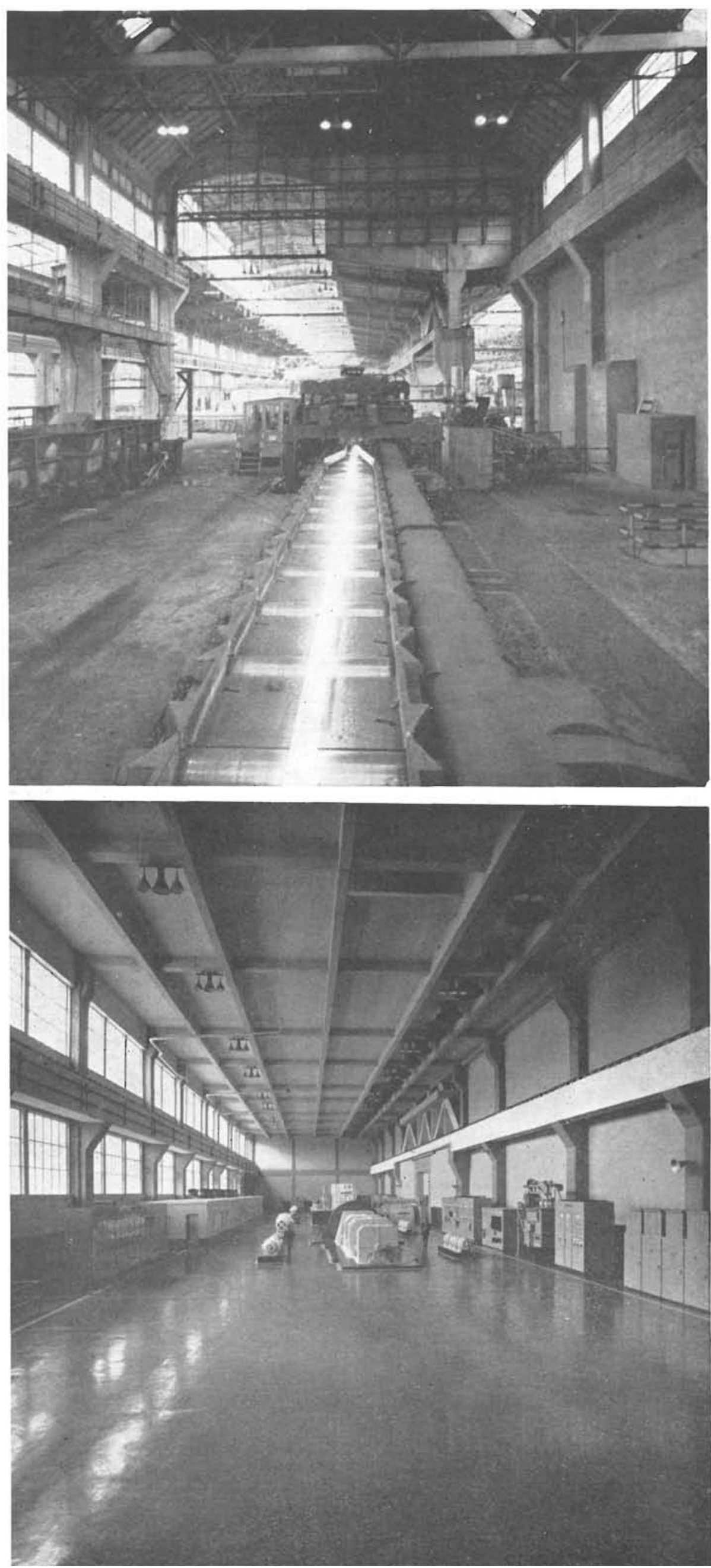

La planta ocupa una extensión de unos $150.000 \mathrm{~m}^{2}$, en los que se distribuyen los distintos elementos de fabricación y acabado.

Está dispuesta para

la fabricación

de una amplia gama de productos siderúrgicos, que abarca desde perfiles y vigas de ala ancha hasta chapa fina en rollos.

La importancia del taller es obvia, si se tiene en cuenta solamente la extensión ocupada y el hecho de que la maquinaria a instalar en él supera las

45.000 toneladas.

Suministran maquinaria las más importantes firmas inglesas, norteamericanas, francesas, alemanas, etc. Es preciso hacer constar que este suministro se ha limitado al estrictamente indispensable. 


\section{laminación}

En la alineación oeste-este, según la cual se ordenan los distintos departamentos de fabricación partiendo del muelle de llegada, la planta de laminación ocupa el extremo E. Conectada con la acerería por un tendido triple de vía, el cual permite la llegada de lingotes y la salida de despuntes y recortes de las secciones de acabado de los distintos trenes. El extremo E. del taller enlaza mediante las necesarias vías con la red general,

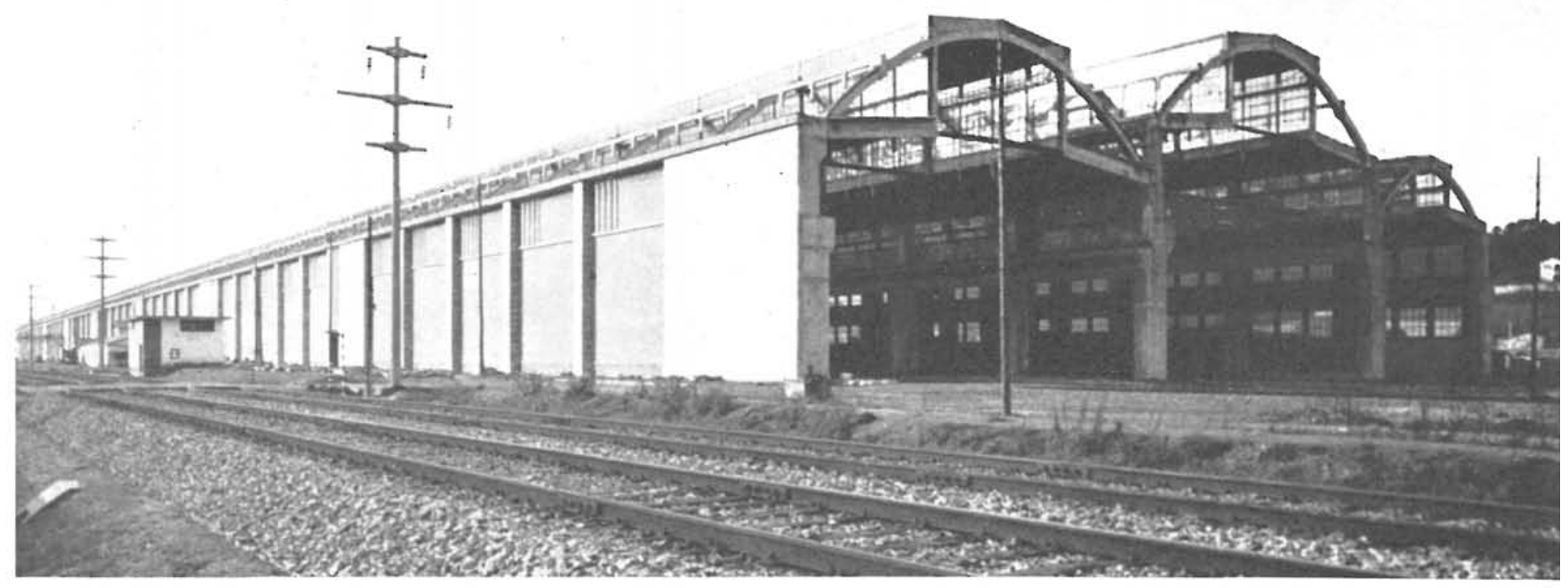

comunicando con la estación de clasificación para la salida de productos al mercado español por ferrocarril y con el parque de almacenamiento del puerto y haciendo posible la salida por vía marítima. 


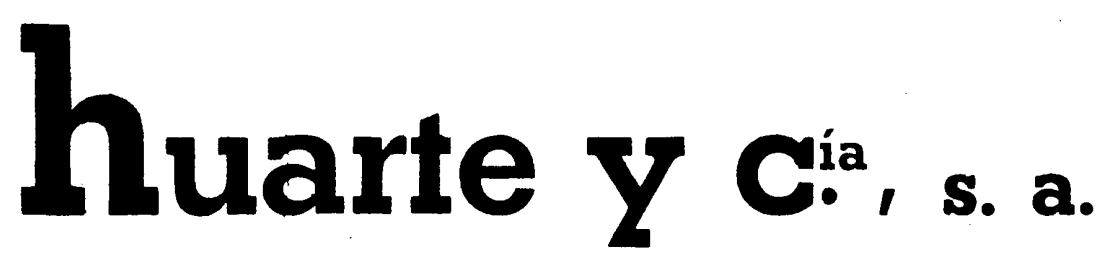

empresa constructora

Avenida del Generalisimo, 8

Teléfono 348207

MADRID - 16

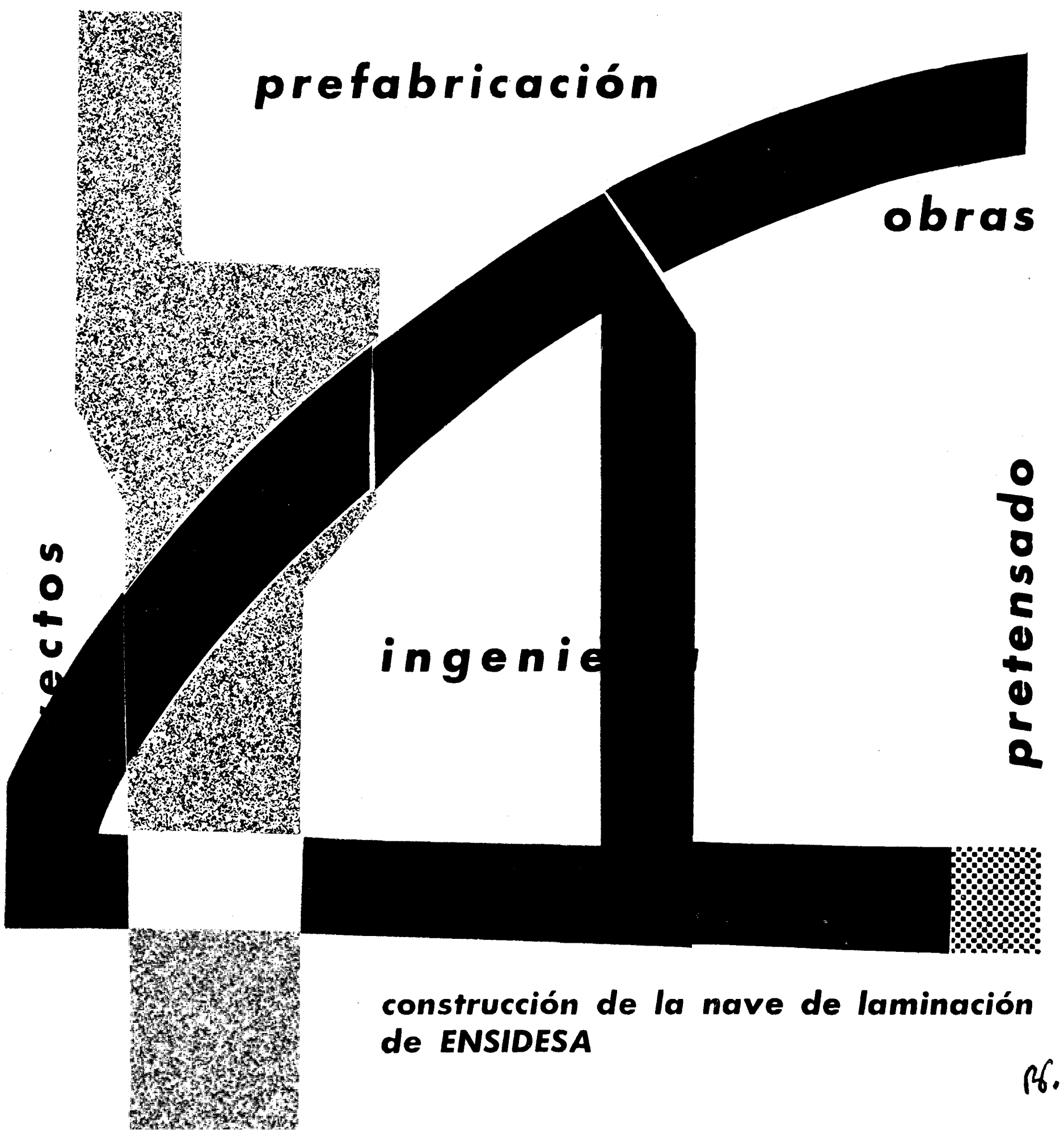




\title{
Urbisı s. a.
}

\section{empresa urbanizadora y constructora}

\author{
Menéndez Pelayo, 71 - Teléf. 510100 - MADRID
}

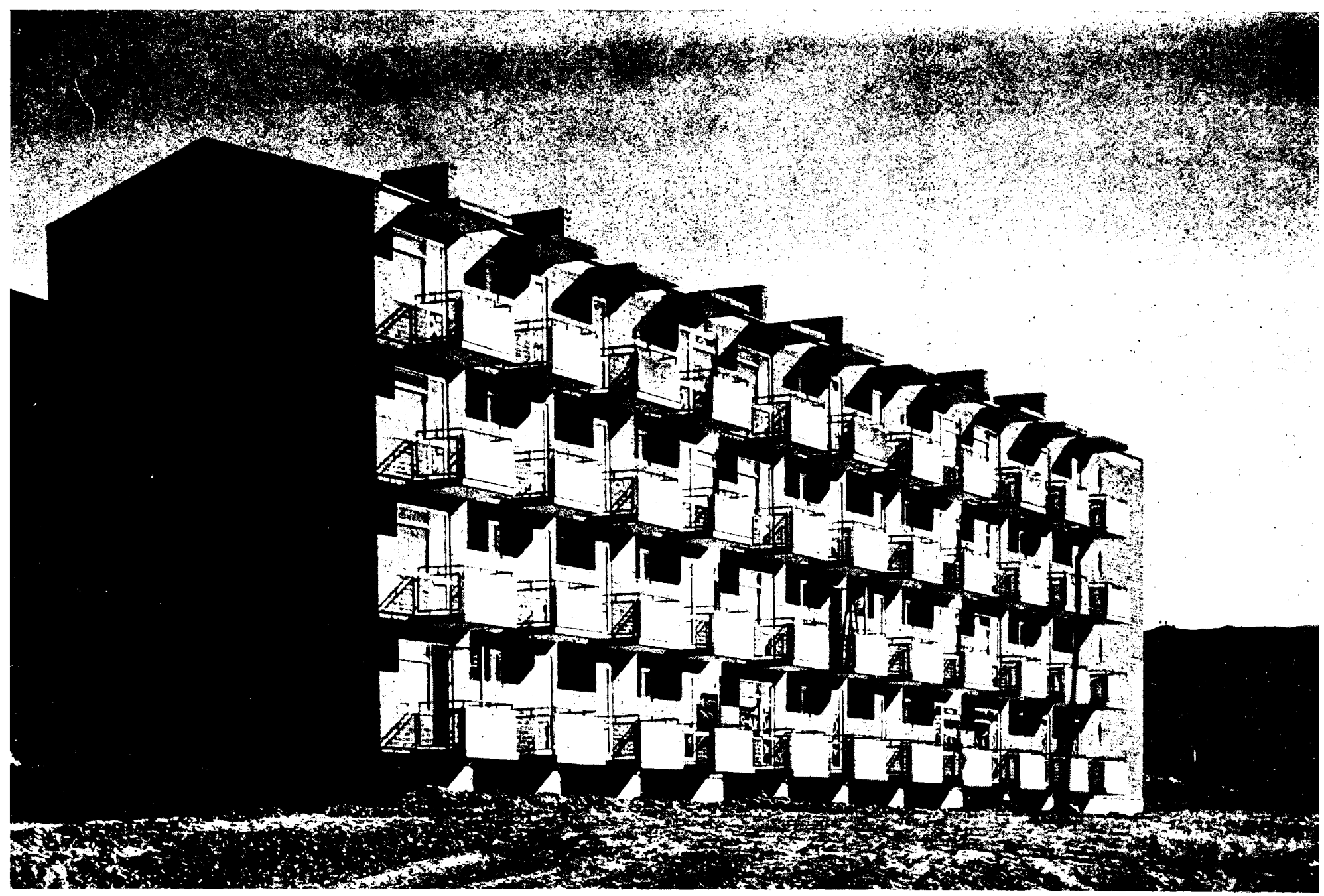

\section{poblado de}

Moratalaz 


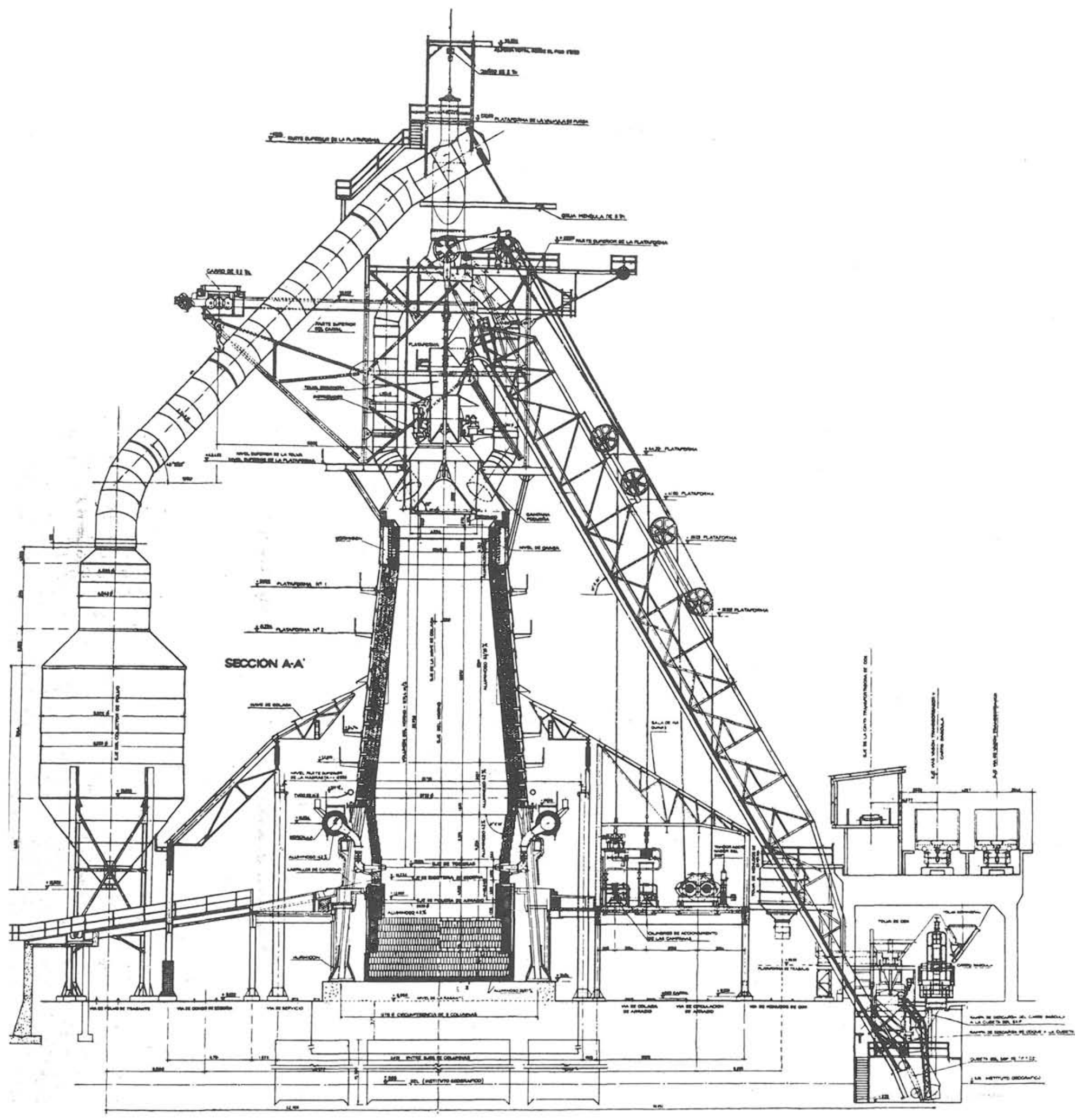

La instalación de sinterización está constituída por un almacén y la máquina de sinterizar. El almacén es un edificio de hormigón. Sus dimensiones son de $32 \times 94 \mathrm{~m}$. La máquina de sinterizar es de tipo de cinta continua, de 36,5 m de largo por 1,83 $\mathrm{m}$ de ancho. Esta instalación se aloja en un edificio de estructura metálica.

Mediante un sistema de cintas, el mineral llega a una estación de carga situada en el extremo de la línea de tolvas. Para los hornos 1 y 2 se dispone de 82 tolvas: 4 se destinan a cok, 14 a caliza y 64 a mineral. Esta línea de tolvas está elevada, y en un nivel superior ruedan tres vagones, de 50 toneladas de capacidad, que se llenan en la estación de carga y, mediante un sistema de descarga lateral, llenan las tolvas. Toda la línea de tolvas está construída en hormigón armado y su conjunto puede almacenar $14.500 \mathrm{t}$ de mineral y $3.400 \mathrm{t}$ de caliza.

Las naves de colada se han ejecutado en construcción mixta, siendo metálica la estructura que rodea el horno; el resto es de hormigón armado. 


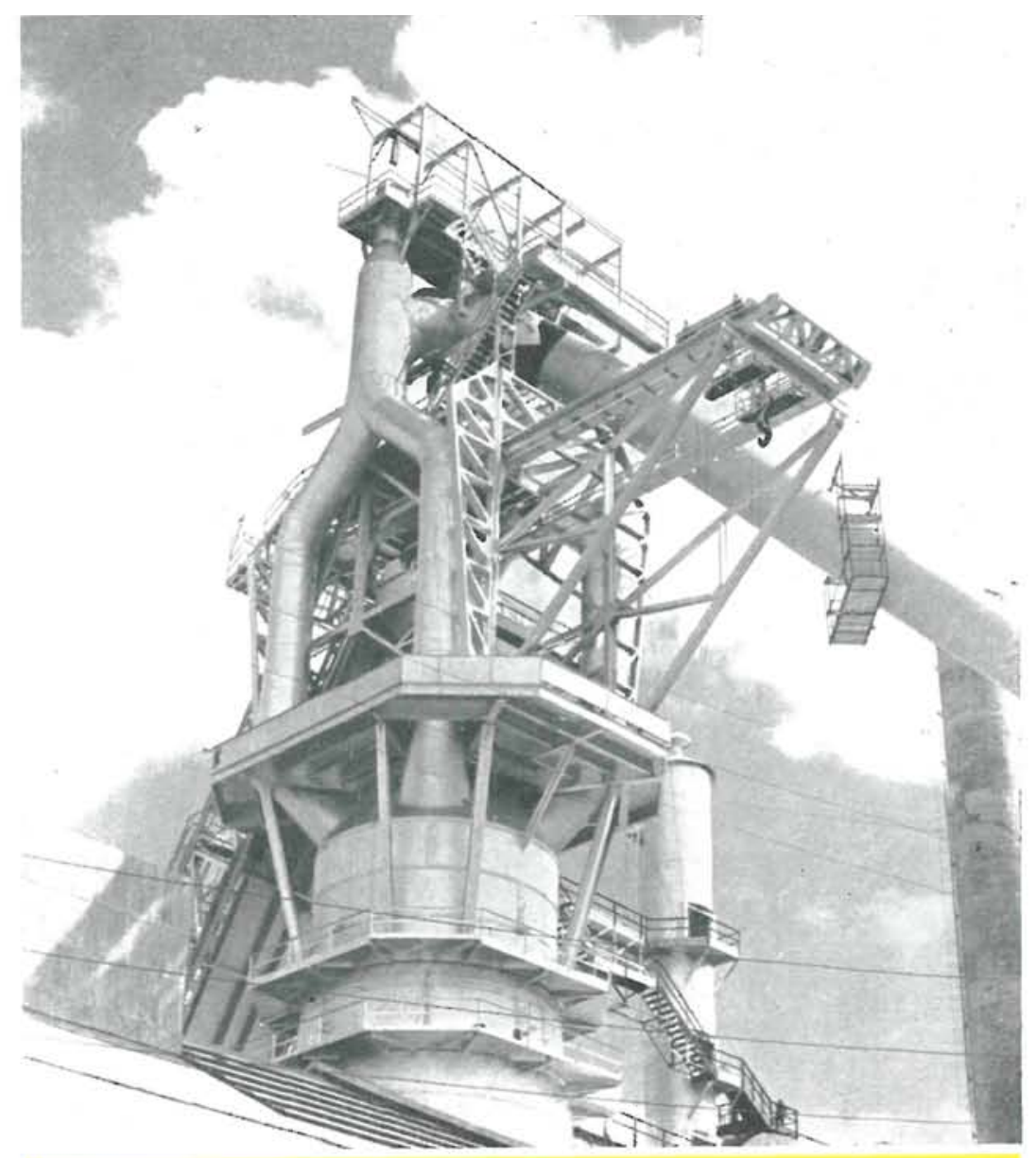

\section{hornos altos}

Las instalaciones de hornos altos se pueden subdividir en tres grupos principales: preparación de materias primas, sinterización y hornos altos.

En la zona de preparación de minerales, las obras principales ejecutadas corresponden a las cimentaciones, siendo las más importantes las correspondientes a la instalación de mezcla de minerales. Dispone esta instalación de un parque de almacenamiento de $320 \times 52 \mathrm{~m}$ y de dos pórticos apiladores de $1.000 \mathrm{t} / \mathrm{h}$ y un pórtico de recogida de $500 \mathrm{t} / \mathrm{h}$. La capacidad de almacenamiento es de unas 250.000 toneladas. El mineral pasa de este parque a la instalación de trituración y clasificación mediante cintas transportadoras. Pasa, seguidamente, a la instalación de mezcla, que tiene una capacidad de almacenaje de 48.000 toneladas.

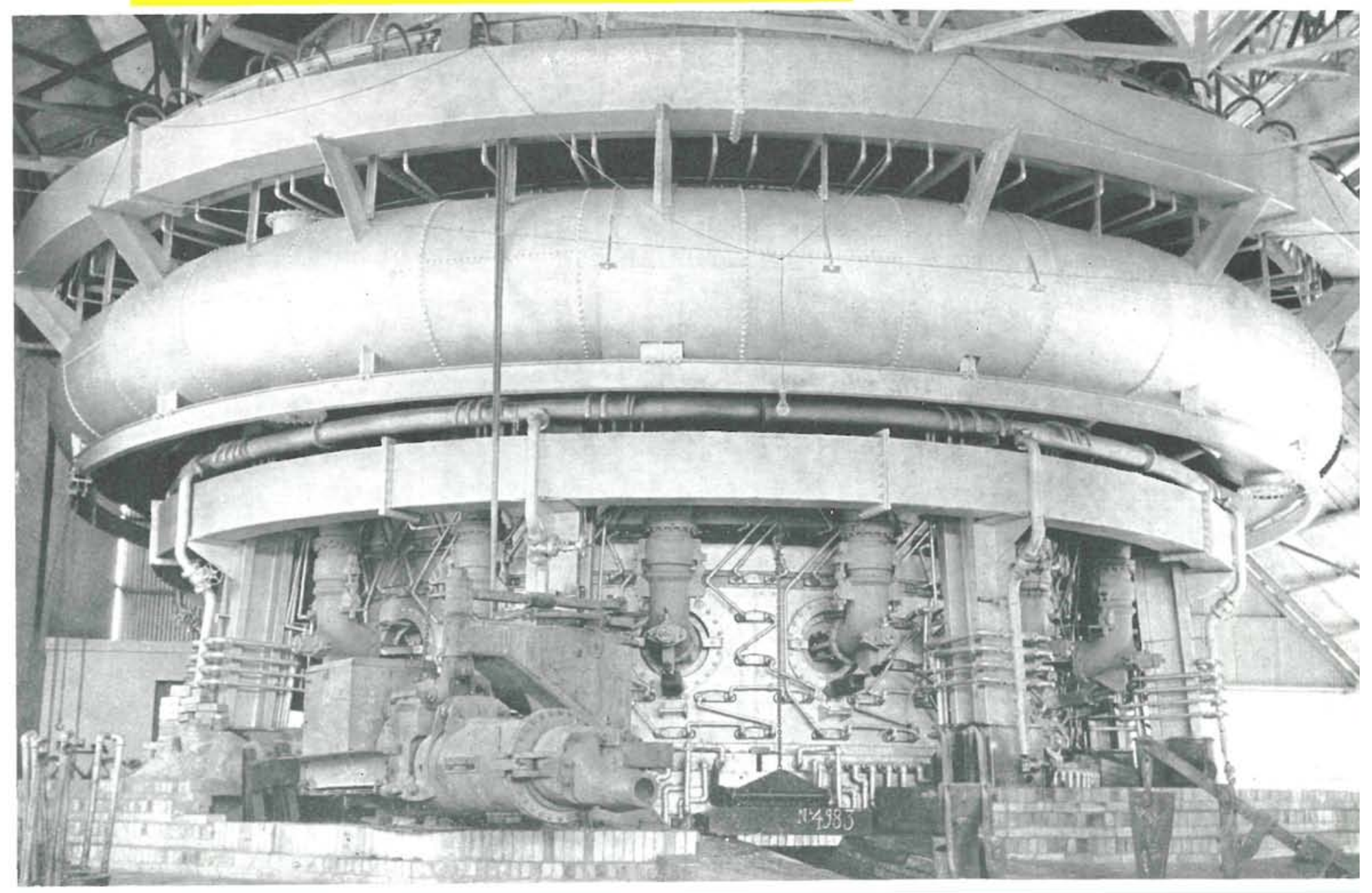



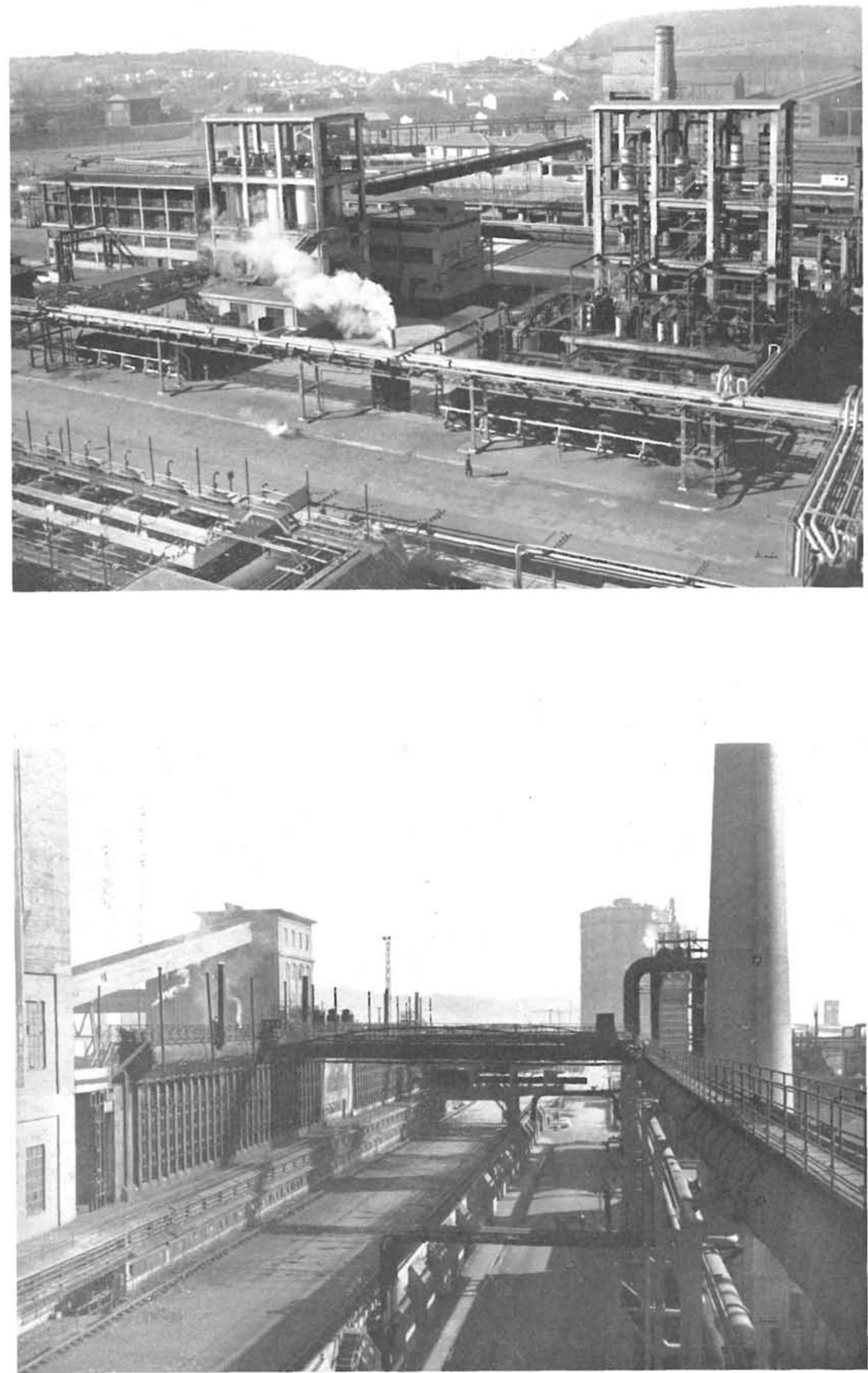

\section{cribadero de cok}

De la rampa de cok se lleva éste mediante una cinta transportadora al cribadero. La cinta descarga en la plataforma superior de este edificio, donde se hace el cribado y clasificación. El edificio está construído en hormigón y es de ocho plantas, con $34 \mathrm{~m}$ de altura.

\section{subproductos}

El gas procedente de los hornos es tratado en una instalación, formada por una serie de torres donde se elimina el amoníaco, el benzol y el alquitrán. El edificio de refrigeradores y lavadores está construído en hormigón armado, y consta de una sola planta que alberga los aparatos de instrumentación y motores de la instalación. Esta zona de subproductos comprende las instalaciones de amoníaco, benzol, alquitrán y sublimación. Entre sus edificios destaca el almacén de sulfato, con una capacidad de 5.000 toneladas. 


\section{hornos de cok}

La instalación comprende cuatro baterías de 30 hornos, estando cada batería cimentada sobre 11 cajones cilíndricos de 5,50 metros de diámetro. Sobre estos cajones se ha construído una placa de hormigón armado, de la cual arrancan los pilares de sustentación de la placa superior que constituye la base de los hornos. Esta placa superior está dispuesta para la conducción de gas a los generadores, colocados sobre ella los regeneradores y encima las cámaras de los hornos y los canales de calefacción. Debido a las fuertes dilataciones que tiene que soportar dicha placa, se hizo un cuidadoso estudio y se armó el conjunto longitudinal y transversalmente efectuando un fuerte anclaje. Adosada a la fachada sur de las baterías se encuentra la plataforma de la vía de la máquina deshornadora, constituída por una placa de hormigón armado cimentada sobre pilotes. En la fachada norte se encuentra la plataforma de la vía del carro-guía y las rampas de cok, cuya cimentación es también de pilotes con superestructura de hormigón armado.

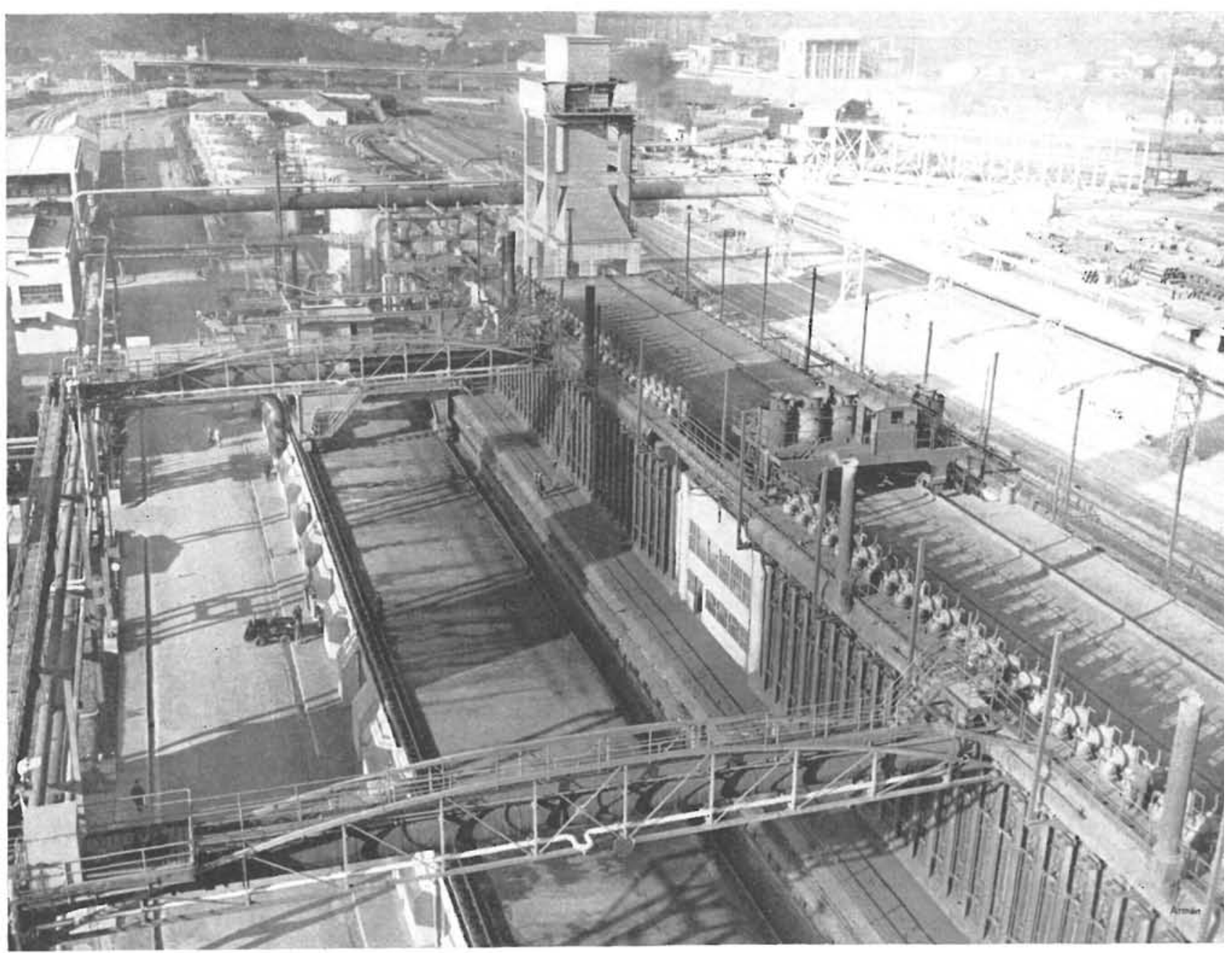


torre de carbón

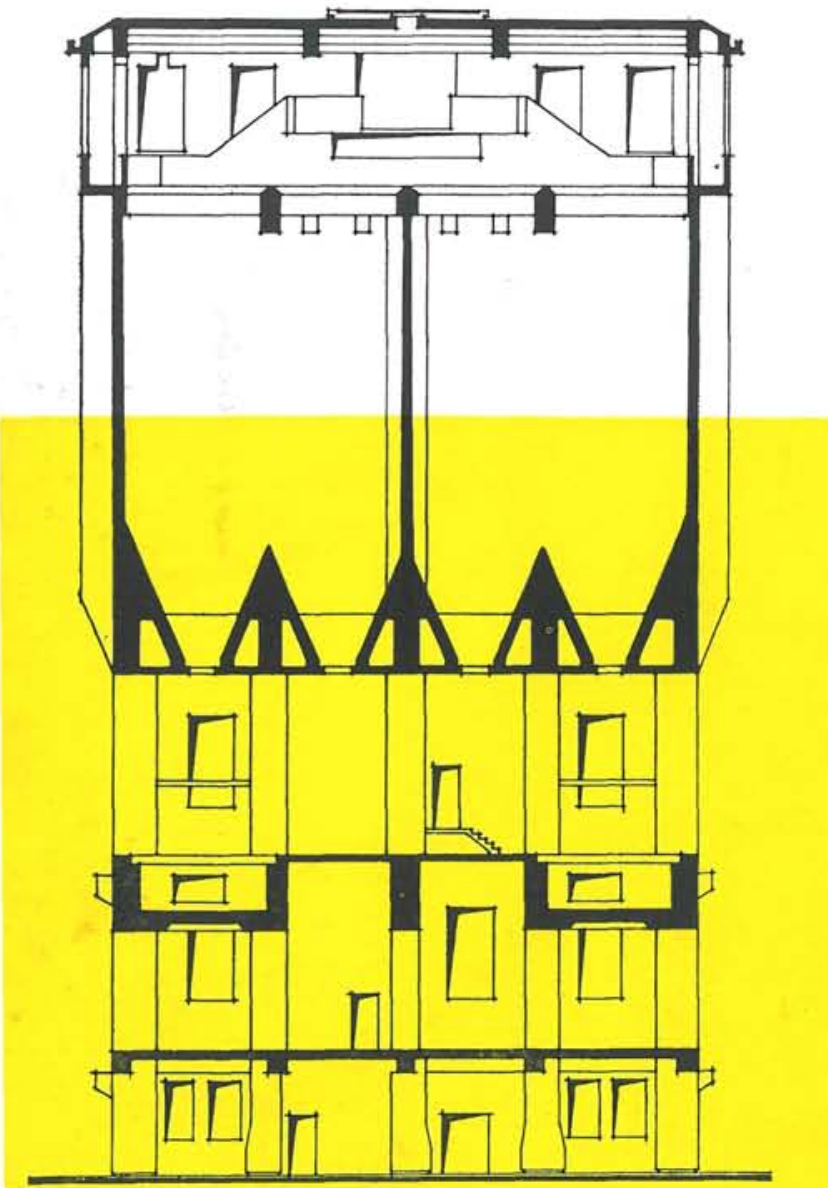

s e c c ión

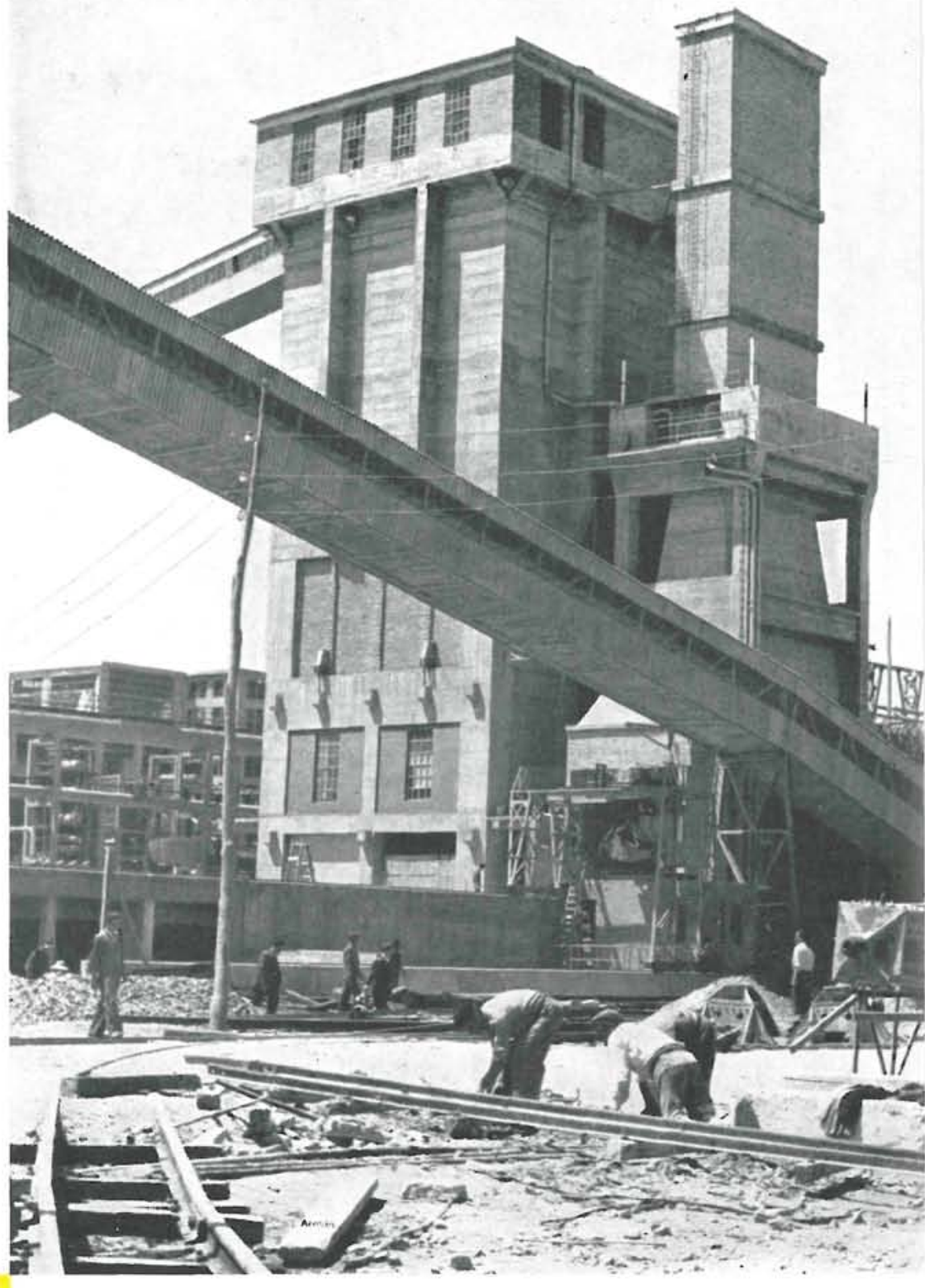

Está situada en el eje de las baterías y tiene adosada en la fachada norte la torre de apagado de cok. Es un edificio construído en hormigón, que tiene $42 \mathrm{~m}$ de altura y en su interior aloja silos capaces para 3.000 toneladas de carbón. El carbón procedente del edificio de moler y mezclar llega mediante cintas transportadoras y se descarga en la parte superior de los silos, y de éstos es descargado a las tolvas del carro de carga. 


\section{I avadero}

\section{e instalación de moler y mezclar}

En el lavadero se hace la separación de las pizarras y mixtos que pueda llevar el carbón. Es un ediflcio de siete plantas, de las cuales cuatro son de estructura de hormigón

y las tres restantes y la cubierta tienen estructura metálica.

La altura total del edificio es de 34 metros y sus dimensiones en planta de $30 \times 20$ metros. Este edificio es contiguo y está relacionado funcionalmente al de moler y mezclar.

En este último se alojan los molinos, mezcladores centrífugos y 10 silos.

El edificio de molido y mezcla tiene estructura de hormigón armado, y sobre un área,

de $21 \times 49,5$ metros, se elevan seis plantas.

Una vez preparada la pasta de carbón para coquizar, se envía mediante cintas transportadoras a la torre de carbón.

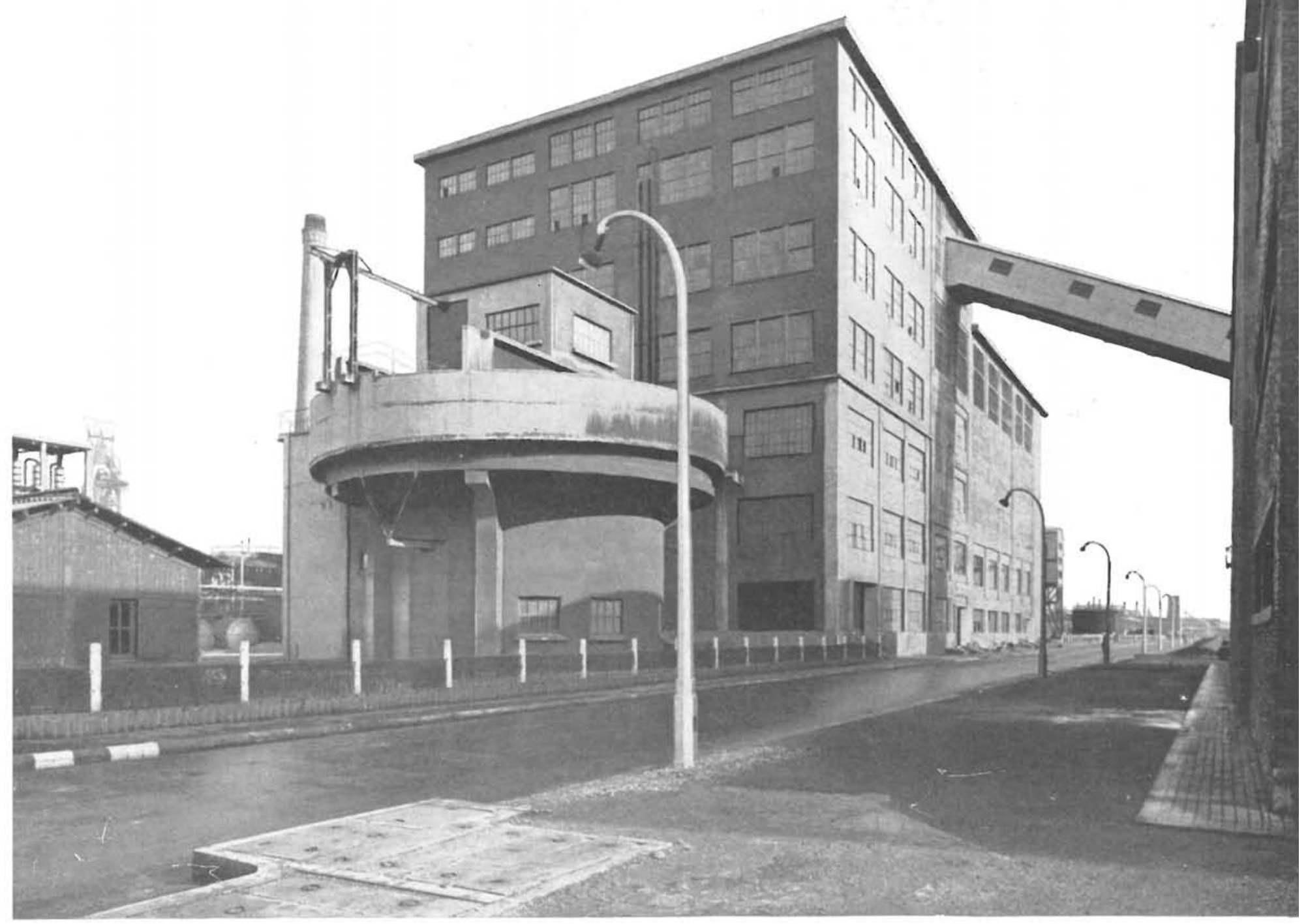




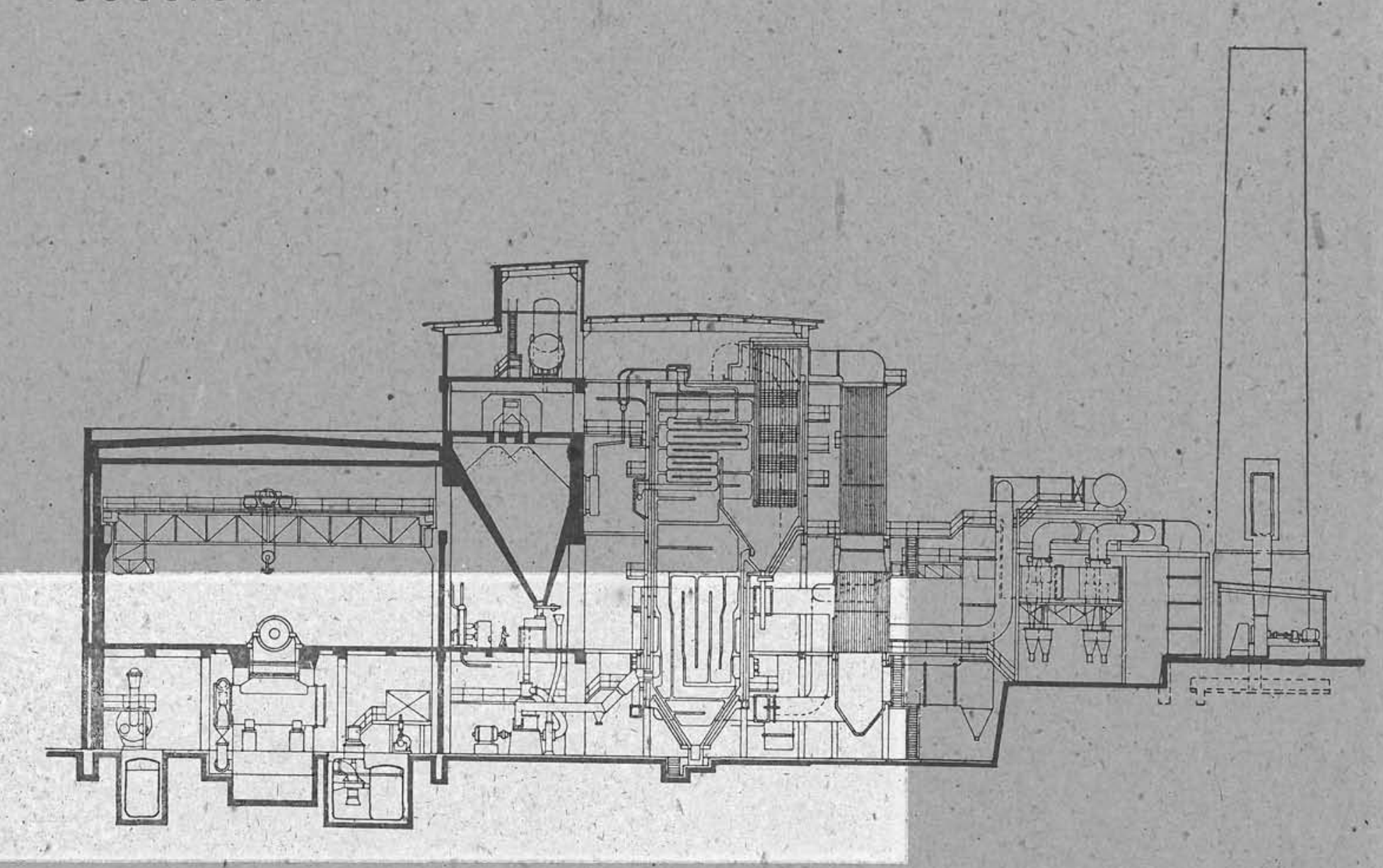

\section{hornos de cok y planta de subproductos}

El conjunto de instalaciones que comprenden los hornos de cok y planta de subproductos ocupa una zona de $210.000 \mathrm{~m}^{2}$, de los cuales están edificados 27.500. El conjunto de la instalación puede agruparse en tres secciones según su función:

- Transporte, almacenamiento, lavado y preparación de carbón cuyos ediflcios principales son el lavadero e instalación de moler y mezclar y la torre de carbón.

b) Hornos de cok e instalaciones de apagado y lavado.

c) Recuperación de subproductos y tratamiento de los mismos. 


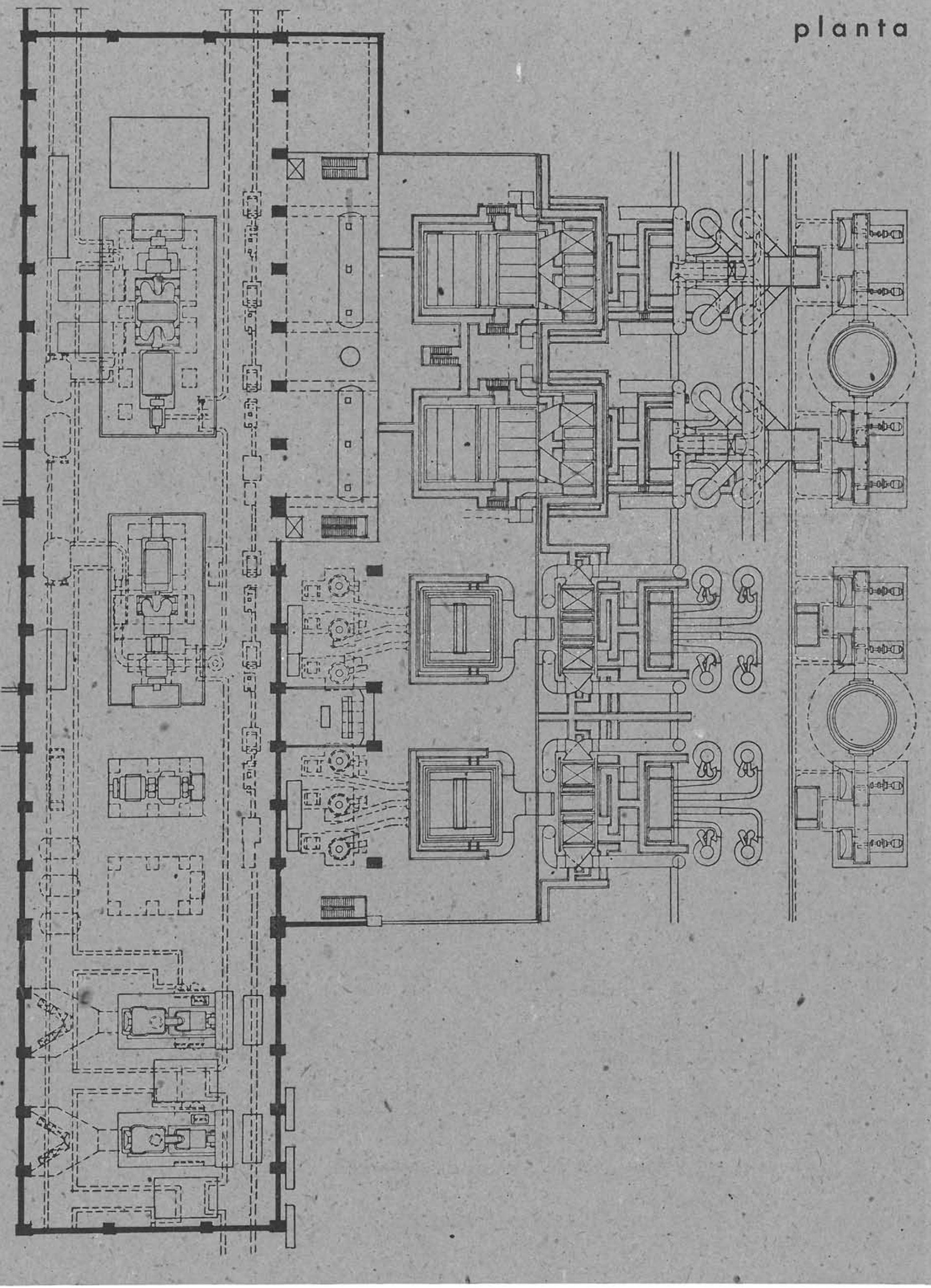


Desde el punto de vista del edificio, existen tres partes diferenciadas: nave de calderas, de estructura metálica con cerramiento de aluminio; nave de silos, de estructura de hormigón, a donde llegan las cintas del parque de carbón; los silos para el mismo y los molinos; sala de máquinas, de $26 \mathrm{~m}$ de luz, servidas por dos puentesgrúa de 80 toneladas, de estructura de hormigón y cubierta metálica.

La central alberga y sirve tres turbosoplantes con una potencia instalada.

Desde la subestación de central térmica se alimentará a $50 \mathrm{kV}$ las subestaciones de aceros, reservas, laminación, talleres, abonos y Endasa, por medio de un anillo de $50 \mathrm{kV}$; y a $6,3 \mathrm{kV}$, los puestos del puerto, preparación de minerales, horno alto y depuración de gas.

Esta central térmica se alimentará también con los excedentes caloríficos de las restantes instalaciones, principalmente el gas de hornos altos y los mixtos del lavadero de carbón.

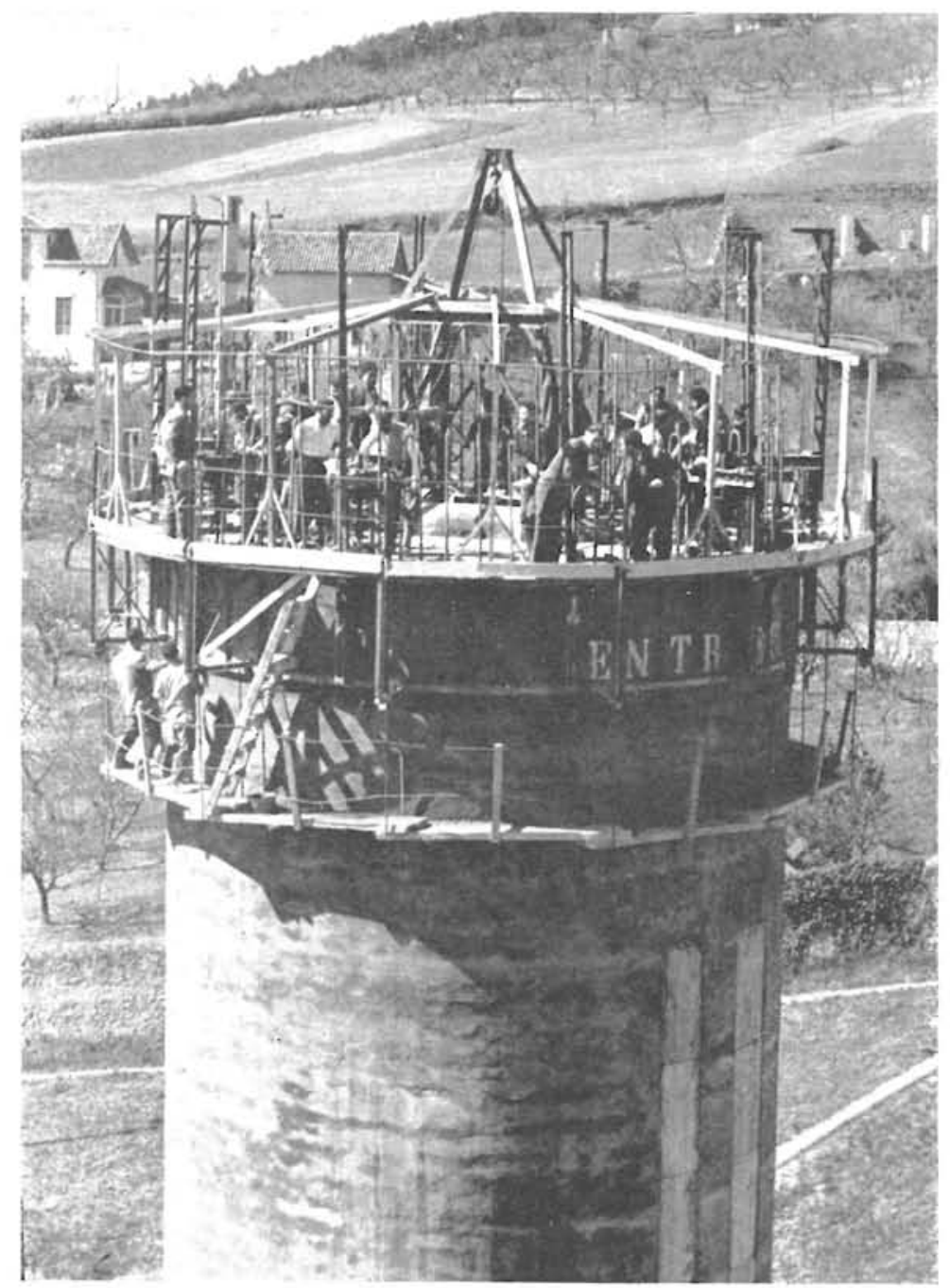

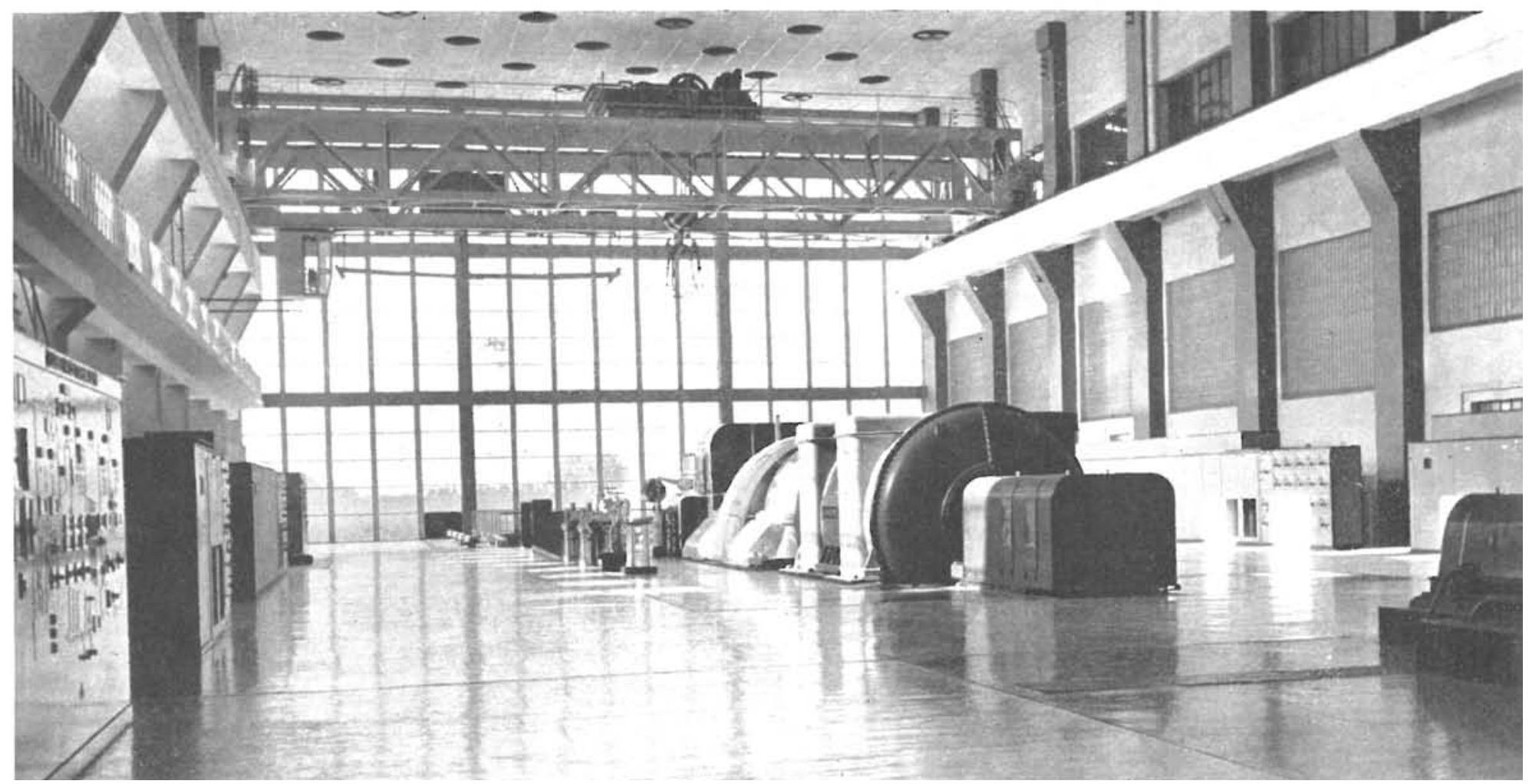




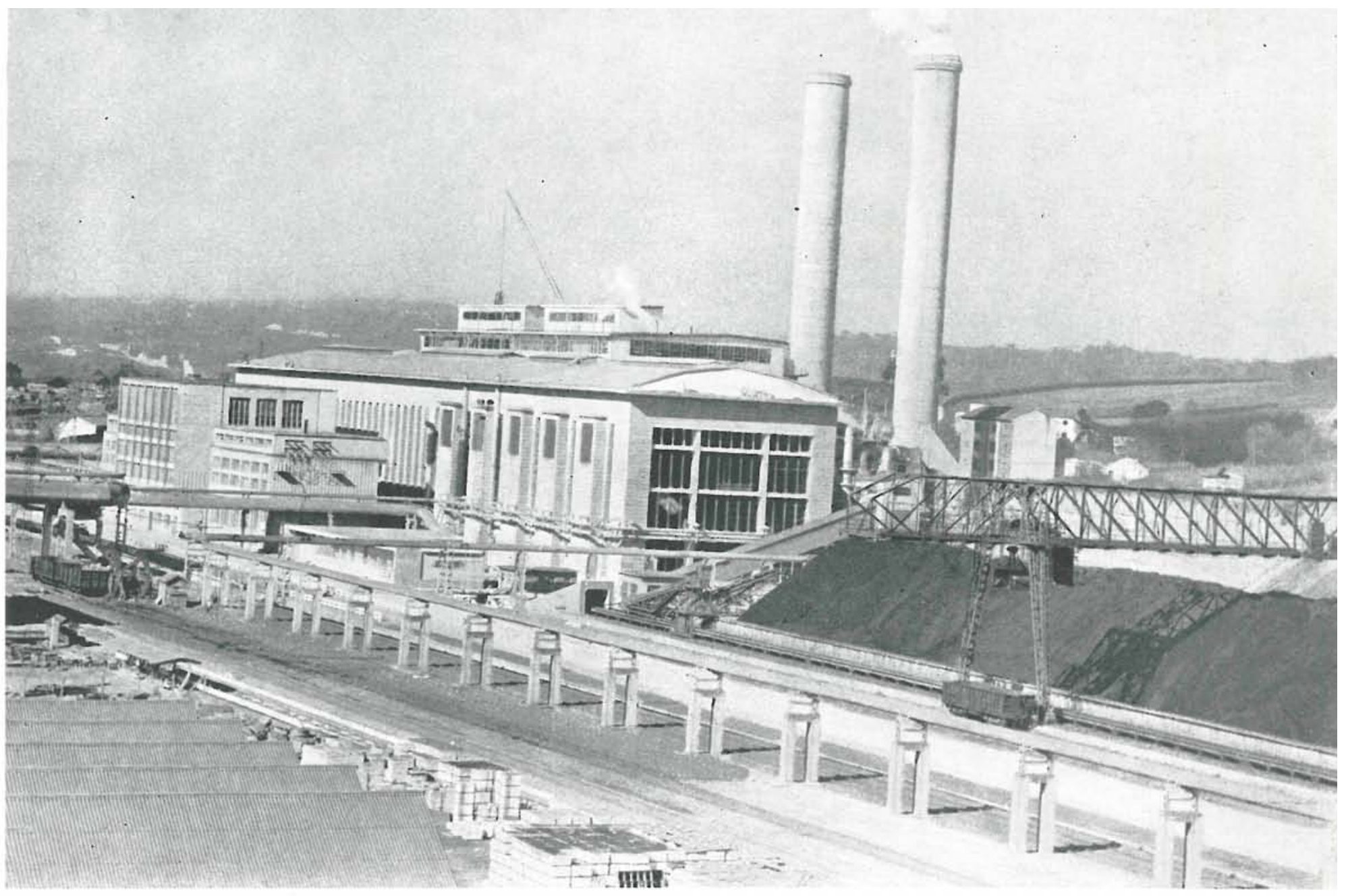

\section{central térmica}

Para el suministro de energía eléctrica a los distintos departamentos y talleres, se ha proyectado una central térmica generadora de la mayor parte de la energía necesaria, así como una serie de subestaciones y puestos de transformación a tensiones de utilización y conversión de corriente alterna.

Fundamentalmente, la central térmica puede considerarse dividida en: central térmica propiamente dicha, constituída por un grupo de $60.000 \mathrm{~kW}$; un grupo de $30.000 \mathrm{~kW}$ y otro de $7.500 \mathrm{~kW}$. En el mismo edificio están alojadas las soplantes para los hornos altos. Como complemento a esta instalación se ha proyectado una subestación para elevar la tensión a 50.000 voltios. Como instalaciones anejas para el servicio se han construído un parque de carbón y una estación depuradora de agua.

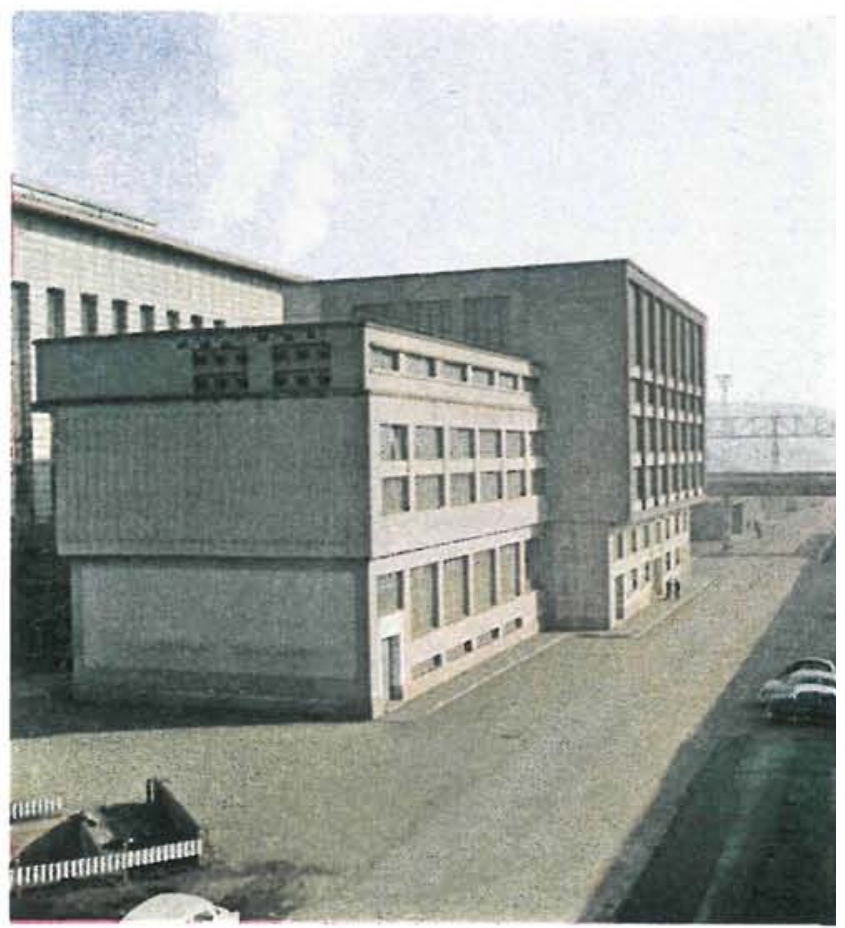

